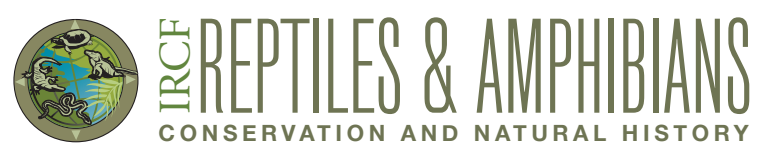

\title{
Notes on the Growth Rates of Anolis sagrei Duméril \& Bibron, 1837 from a Small Betelnut Palm (Areca catechu, L.) Plantation in Southwestern Taiwan
}

\author{
Gerrut Norval ${ }^{1 *}$, Shao-Chang Huang ${ }^{2}$, and Jean-Jay Mao ${ }^{3}$ \\ ${ }^{1}$ Applied Behavioural Ecology and Ecosystem Research Unit, Department of Environmental Sciences, University of South Africa, Republic of South Africa \\ (gnorval@gmail.com) \\ ${ }^{2}$ Queensland Brain Institute, The University of Queensland, St. Lucia, Queensland, Australia \\ ${ }^{3}$ Department of Forestry and Natural Resources, National Ilan University, Ilan, Taiwan, R.O.C.
}

Photographs by the senior author.

Abstract.-We collected and individually marked 210 male and 143 female Anolis sagrei from a small Betelnut Palm (Areca catech $u$, L.) plantation in Santzepu, Sheishan District, Chiayi County, southwestern Taiwan, during the period mid-January through mid-December 2004. Of these 353 lizards, only 35 males and 17 females were recaptured and used to calculate monthly growth rates and monthly growth percentages. Results indicated that at least some individuals experienced active growth throughout the year, that smaller individuals of both sexes grew faster than larger conspecifics of the same gender, and that males grew faster than females. We also determined that growth rates of both sexes decreased during the peak reproductive period.

Brown Anoles (Anolis sagrei Dumeril and Bibron 1837; Fig. 1) are native to Cuba, the Bahamas, the Atlantic coast of México

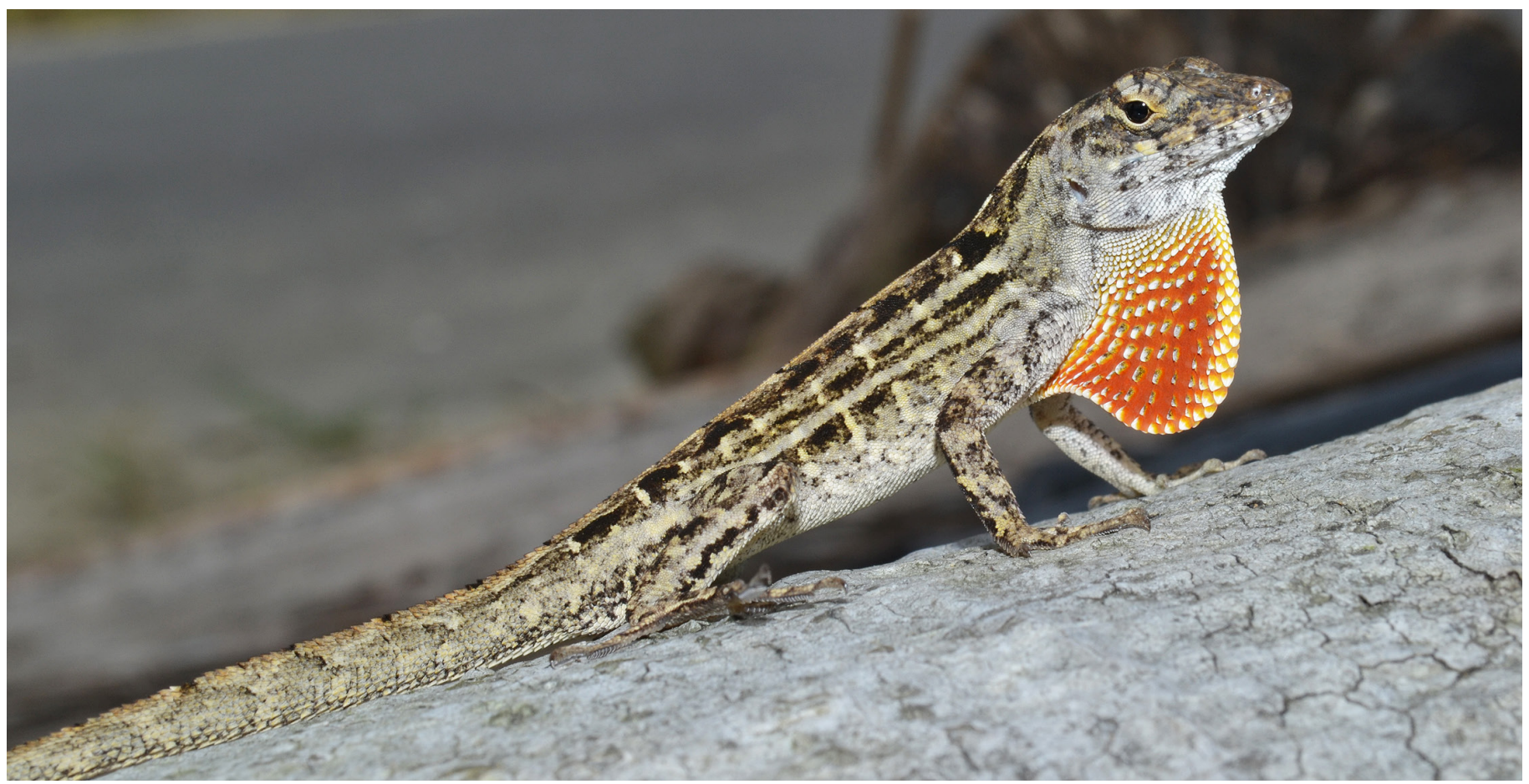

Fig. 1. An adult male Anolis sagrei from the Santzepu sampling area, Taiwan. 
to Belize, as well as islands such as Swan Island (Honduras), Cayman Brac, and Little Cayman (Williams 1969, Schwartz and Henderson 1991, Losos et al. 1993, Rodriguez Schettino 1999). This species has been widely introduced (Kraus 2009) and is an exotic invasive lizard species in Taiwan (Norval et al. 2002, Chang 2007).

Anolis sagrei is highly sexually dimorphic in size (Fig. 2) and shape (Schwartz and Henderson 1991, Rodriguez Schettino 1999, Butler et al. 2000), but the magnitude of the sexual size dimorphism varies geographically (Lee 1987, Campbell and Echternacht 2003). The relatively larger body

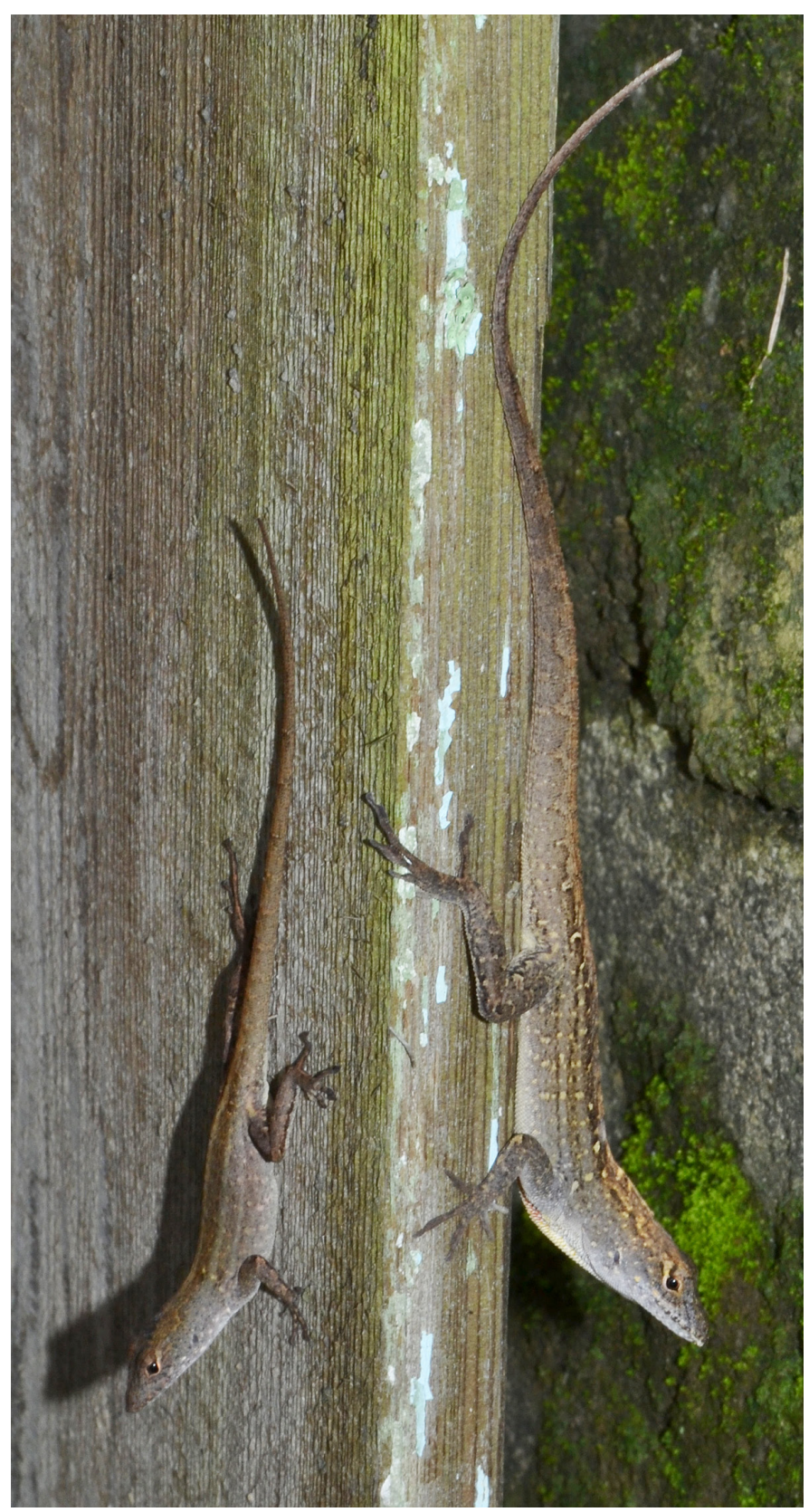

Fig. 2. An adult pair of Anolis sagrei from the Santzepu sampling area, Taiwan, clearly illustrates the differences in sizes of females (left) and males (right). size of males is attributable to a greater growth spurt and continued investment in growth, as opposed to females that allocate considerable energy to egg production (Schoener and Schoener 1978). However, populations that are sympatric with ecologically similar species can demonstrate reductions in sexual size dimorphism (SSD) as a consequence of interspecific competition for limited resources that appears to limit the total range of sizes of individuals of any one species (Lister 1976, Schoener and Schoener 1978, Losos 2009). In addition, climatic conditions, such as extended periods of rainfall, can interfere with feeding (Schoener and Schoener 1978) and, as a result, the sizes and growth rates of individuals.

Because lizards reach sexual maturity at certain sizes, the elucidation of growth rates is important in understanding the natural history of a species. In this study, we contribute to the understanding of the ecology of $A$. sagrei in Taiwan by providing descriptions of growth discerned from a markrecapture study.

\section{Methods}

We obtained meteorological data from the Taiwanese Central Weather Bureau website (http://www.cwb.gov.tw/V6e/index. $\mathrm{htm}$ ) for Chiayi City, which is located about $5 \mathrm{~km}$ from the study area.

From mid-January through mid-December 2004, we collected $A$. sagrei on an ad hoc basis from a small Betelnut Palm (Areca catechu, L.) plantation in Santzepu, Sheishan District, Chiayi County, southwestern Taiwan (N2325'46”, E120'28'55"; WGS84) as part of the ongoing research on the impact of this invasive taxon on native species. Every lizard collected for the first time was sexed based on the presence or absence of enlarged post-cloacal scales (only present in males) and the size of the dewlap (larger in males). We then measured the snout-vent length (SVL) and tail length (TL) to the nearest $\mathrm{mm}$ with a transparent plastic ruler. The condition of the tail was assessed based on scalation and scored as an original tail, regenerated tail, or broken tail. If the lizard had a regenerated tail, the regenerated portion was also measured to the nearest $\mathrm{mm}$. The animal was then weighed (body mass) to the nearest $0.1 \mathrm{~g}$ with a digital scale. Each lizard was marked with a unique toe-clip pattern for permanent identification and released at the locality where it had been captured. We assessed the condition of the tail, and measured SVL, TL, and mass for every recaptured lizard before releasing it again at the site of capture.

As for introduced populations in Belize, Florida, Hawaii, and Jamaica, the minimum size for sexually mature females in Taiwan is ca. $34 \mathrm{~mm}$ (Licht and Gorman 1970, Sexton and Brown 1977, Lee et al. 1989, Goldberg et al. 2002, Norval et al. 2012a), but Taiwanese males with SVLs $<39 \mathrm{~mm}$ can be sexually mature. However, such small males are unlikely to compete successfully with larger territorial males and prob- 
ably invest more energy in growth than reproduction and territorial interactions. Therefore, for this study, we considered male lizards to be sexually mature at $S V L \geq 39 \mathrm{~mm}$ and females at $S V L \geq 34 \mathrm{~mm}$.

For this study, we used data only for lizards that were recaptured at least once. Because we could not rule out the possibility of tail loss during capture and lizards often could not be correctly categorized as having original or regenerated tails, recaptured lizards that had suffered tail loss (caudal autonomy) but lacked indications of tail regeneration (i.e., broken tail) were excluded from the analysis. For remaining recaptures, at every recapture event, we calculated an estimated monthly growth rate (MGR) using the following formula (Okada et al. 2002):

\section{$\operatorname{MGR}(\mathrm{mm} / \mathrm{mo})=$ \\ (growth in SVL/days between the captures) x 30}

Since very few of the lizards were recaptured on a monthly basis, the MGR values were assigned to the month in which the lizards were recaptured. In order to express MGR in relation to SVL, we also calculated the monthly growth percentage (MG \%) for every recapture, first using the formula:

\section{Growth percentage $=$}

[(SVL at present capture/SVL at previous capture)-1] x 100

and then using that result in the formula:

$$
\begin{aligned}
& \text { MG \% (\%/month) }= \\
& \text { (growth percentage/days between captures }) \times 30
\end{aligned}
$$

Because $\log 10$ transformation failed to normalize the distribution of some of the samples, we compared SVL MG \% and TL MG \% of males and females using untransformed data in nonparametric Mann-Whitney U-tests. To test for a correlation between SVL and the growth rate, we pooled data for lizards with original and regenerated tails. We used Spearman's rank correlation coefficient $\left(r_{s}\right)$ to examine relationships between SVL at previous capture and subsequent SVL MG \% for every recapture event. For all statistical analyses, we used Prism 6
(Graphpad Software, San Diego, CA). Means are presented \pm one SD. For all statistical tests, $a=0.05$.

\section{Results}

Mean temperature for the study period was $23.49 \pm 4.25^{\circ} \mathrm{C}$. August was the hottest month and January the coldest (Fig. 3). Precipitation during the study period was $1,411 \mathrm{~mm}$, most of which was in July (Fig. 4).

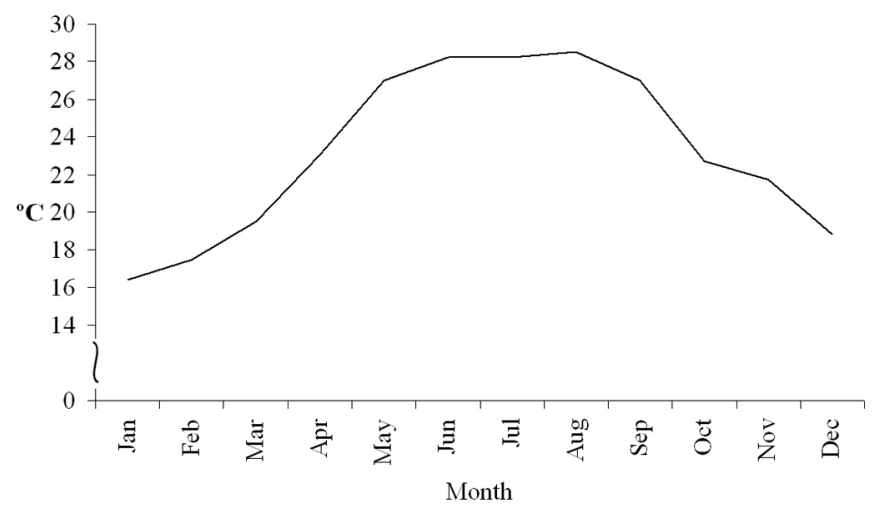

Fig. 3. The mean temperature $\left({ }^{\circ} \mathrm{C}\right)$ during the period January to December 2004 in the Santzepu sampling area, Taiwan.

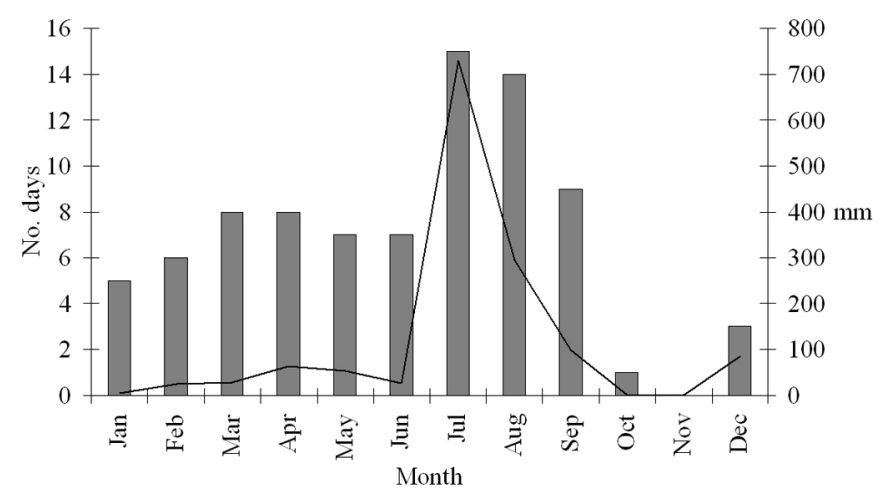

Fig. 4. Monthly total rainfall (line) and the number of rainy days (bars) during the period January to December 2004 in the Santzepu sampling area, Taiwan.

Table 1. Range, mean \pm SD (in parentheses), and median (in brackets) of snout-vent lengths (SVL), tail lengths (TL), TL to SVL ratio (TLR), and, where applicable, the regenerated portion of the tail as a percentage (RP \%) for Anolis sagrei from Santzepu (data from recapture events are included).

\begin{tabular}{lllll} 
& \multicolumn{2}{c}{ Male } & \multicolumn{1}{c}{ Female } & \multicolumn{2}{c}{ Lizards with regenerated tails } \\
& 54 & 46 & 24 & \multicolumn{1}{c}{ Female } \\
\hline $\mathrm{n}$ & & \multicolumn{1}{c}{ Male } & 9 \\
\hline $\mathrm{SVL}(\mathrm{mm})$ & $27-61(47.8 \pm 7.9)[49]$ & $34-54(42.0 \pm 4.6)[42.5]$ & $40-62(55.1 \pm 5.9)[57]$ & $40-47(42.1 \pm 2.2)[42]$ \\
\hline $\mathrm{TL}(\mathrm{mm})$ & $50-129(94.7 \pm 18.0)[94]$ & $69-98(80.6 \pm 7.2)[80.5]$ & $12-95(67.3 \pm 19.9)[70]$ & $38-74(61.8 \pm 12.3)[69]$ \\
\hline $\mathrm{TLR}$ & $1.7-2.2(2.0 \pm 0.1)[2.0]$ & $1.8-2.1(1.9 \pm 0.1)[1.9]$ & $0.3-1.7(1.2 \pm 0.4)[1.3]$ & $0.9-1.8(1.5 \pm 0.3)[1.6]$ \\
\hline $\mathrm{RP} \%$ & $* * *$ & $* * *$ & $1.2-69.6(42.9 \pm 21.9)[49.6]$ & $21.7-69.8(41.8 \pm 17.2)[40]$ \\
\hline
\end{tabular}


Table 2. Range, mean \pm SD (in parentheses), and median (in brackets) of the snout-vent length monthly growth rate (SVL MGR), snoutvent length monthly growth percentage (SVL MG \%), tail length monthly growth rate (TL MGR), and tail length monthly growth percentage (TL MG \%) for Anolis sagrei from Santzepu.

Lizards with original tails Male
Female
Lizards with regenerated tails Male

\begin{tabular}{lllll}
\hline$n$ & 28 & 28 & 24 & 8 \\
\hline SVL MGR & $0.0-5.8(2.5 \pm 1.8)[2.8]$ & $0.0-6.7(1.5 \pm 2.0)[0.8]$ & $0.0-8.6(1.7 \pm 1.9)[1.4]$ & $0.0-2.9(1.2 \pm 1.1)[1.1]$ \\
\hline SVL MG \% & $0.0-14.9(6.1 \pm 4.9)[6.2]$ & $0.0-18.0(3.8 \pm 5.1)[2.0]$ & $0.0-15.3(3.4 \pm 3.7)[2.5]$ & $0.0-6.9(3.0 \pm 2.7)[2.7]$ \\
\hline TL MGR & $1.6-11.0(5.5 \pm 3.0)[5.3]$ & $0.0-8.6(2.2 \pm 2.7)[1.1]$ & $0.0-41.4(8.9 \pm 11.3)[4.3]$ & $0.0-21.2(6.9 \pm 7.6)[4.2]$ \\
\hline TL MG \% & $1.4-20.0(7.1 \pm 5.4)[5.5]$ & $0.0-10.7(2.8 \pm 3.4)[1.4]$ & $0.0-154.3(29.5 \pm 48.4)[5.7]$ & $0.0-235.8(37.6 \pm 80.8)[6.5]$ \\
\hline
\end{tabular}

Table 3. Results of Mann-Whitney U-tests comparing monthly growth percentage comparisons of male and female Anolis sagrei with original and regenerated tails. Asterisks $\left({ }^{*}\right)$ mark statistically significant differences.

\begin{tabular}{|c|c|c|c|c|}
\hline \multirow[b]{2}{*}{ TL MG \% } & \multicolumn{4}{|c|}{ SVL MG \% } \\
\hline & $\begin{array}{c}\text { Males } \\
\text { (original tails) }\end{array}$ & $\begin{array}{c}\text { Females } \\
\text { (original tails) }\end{array}$ & $\begin{array}{c}\text { Males } \\
\text { (regenerated tails) }\end{array}$ & $\begin{array}{c}\text { Females } \\
\text { (regenerated tails) }\end{array}$ \\
\hline $\begin{array}{l}\text { Males } \\
\text { (original tails) }\end{array}$ & - & $\begin{array}{l}U=276.5 \\
\mathrm{P}=0.057\end{array}$ & $\begin{array}{c}U=226.5 \\
\mathrm{P}=0.043^{*}\end{array}$ & NA \\
\hline $\begin{array}{l}\text { Females } \\
\text { (original tails) }\end{array}$ & $\begin{array}{c}U=163.0 \\
\mathrm{P}=0.0001^{*}\end{array}$ & - & NA & $\begin{array}{l}U=104.5 \\
\mathrm{P}=0.784\end{array}$ \\
\hline $\begin{array}{l}\text { Males } \\
\text { (regenerated tails) }\end{array}$ & $\begin{array}{l}U=293.0 \\
\mathrm{P}=0.436\end{array}$ & NA & - & $\begin{array}{c}U=96.0 \\
P>0.999\end{array}$ \\
\hline $\begin{array}{l}\text { Females } \\
\text { (regenerated tails) }\end{array}$ & NA & $\begin{array}{c}U=67.0 \\
P=0.085\end{array}$ & $\begin{array}{c}U=92.0 \\
\mathrm{P}=0.872\end{array}$ & - \\
\hline
\end{tabular}

We collected and marked 210 male and 143 female $A$. sagrei during the study period. At first capture, mean male SVL was $47.4 \pm 7.9 \mathrm{~mm}(27-61 \mathrm{~mm})$, mean TL was $82.7 \pm$ $24.8 \mathrm{~mm}(8-128 \mathrm{~mm})$, and mean body mass was $3.1 \pm 1.4 \mathrm{~g}$ (0.6-6.6 g). Mean female SVL at first capture was $37.9 \pm 4.8$ $\mathrm{mm}(24-48 \mathrm{~mm})$, mean TL was $64.0 \pm 18.4 \mathrm{~mm}(9-92 \mathrm{~mm}$, and mean body mass was $1.5 \pm 0.5 \mathrm{~g}(0.4-2.8 \mathrm{~g})$.

Only 38 males and 25 females were recaptured at least once. The mean recapture interval for males was $45 \pm 40.0$ days

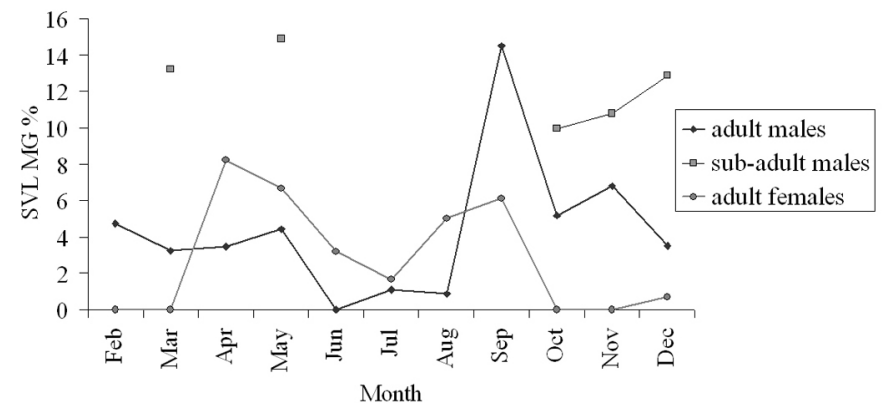

Fig. 5. Growth patterns of Anolis sagrei from the Santzepu sampling area, Taiwan.
(2-217 days), whereas that for females was $67.5 \pm 57.0$ (7-278 days). Three recaptured males and eight females were excluded from analyses because they had broken tails. Sizes of males and females in this study are given in Table 1, growth rates are shown in Table 2, and growth patterns are illustrated in Fig. 5.

Males with original tails had significantly greater median SVL MG \% than males with regenerated tails and median TL MG \% of males with original tails was significantly greater than that for females with original tails (Table 3). However, if

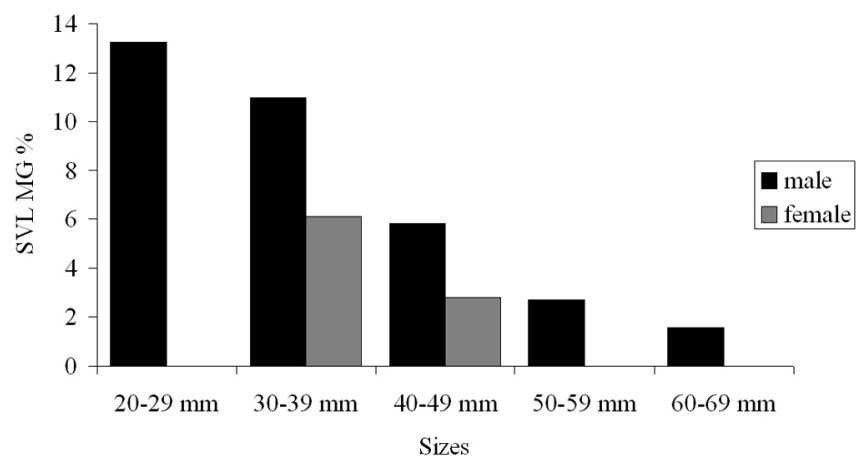

Fig. 6. The mean snout-vent length growth percentage (SVL MG\%) of different size classes of male and female Anolis sagrei. 
sub-adults ( $\mathrm{SVL}<39 \mathrm{~mm}$ ) are excluded from the analyses, no statistically significant differences in SVL MG \% are evident $(\mathrm{U}=222.5 ; \mathrm{P}=0.177)$. We also found that males can regenerate an autotomized tail at an average rate of $8.9 \pm 11.3 \mathrm{~mm}$ per month, and females at an average rate of $6.9 \pm 7.6 \mathrm{~mm}$ per month.

Mean SVL MG \% was highest in smaller size classes and decreased in larger size classes (Fig. 6). A statistically significant negative correlation existed between mean SVL MG \% and SVL at previous capture for both males $\left(\mathrm{r}_{s}=-0.684 ; \mathrm{P}<\right.$ $0.0001)$ and females $\left(r_{s}=-0.336 ; P=0.045\right)$.

In our study very few lizards were recaptured in more than two consecutive months. In 26 instances involving males and 16 involving females, we recaptured individuals in two consecutive months. Such males were recorded in every month, and of these males, $84.6 \%$ had experienced growth. Females were recaptured less frequently, and females that were recaptured in two consecutive months were recorded in every month except February, July, and September, and of these females, 56.3\% had experienced growth. As a whole, these recapture events indicate that growth occurs throughout the year in at least some individuals.

\section{Discussion}

Although too few individuals (especially females) were recaptured for a detailed description of growth rates of $A$. sagrei in southwestern Taiwan, some conclusions can be deduced from the results. Indications of growth in at least some individuals were evident throughout the study period. Since ecdysis (skin shedding) is evidence of reptilian growth (Zug et al. 2001) and anoles consume the slough (dermatophagy; Fig. 7), the presence of skin in the stomach of a specimen is indicative of growth in the period prior to collection. In a dietary study of A. sagrei conducted over a 15 -month period in southwestern Taiwan (Norval et al. 2010), remains of sloughed skin were found in the stomachs of some individuals taken in every month except October, which is suggestive of growth throughout the year. The results of our study provide further support for this observation.

Schwartz and Henderson (1991) stated that female A. sagrei have a life expectancy of ca. 1.8 years, whereas that of males is about one year, indicating that $A$. sagrei is a short-lived species. Consequently, immature individuals would be expected to have a fast growth rate that would permit them to reach sexually maturity in a relatively short period. Cox et al. (2009) stated that even though hatchling males and females do not differ in SVL, males grow significantly larger due to a significantly faster growth rate that starts immediately after hatching. Unfortunately, we obtained no growth data for sexually immature females ( $\mathrm{SVL}<34 \mathrm{~mm}$ ), so we cannot compare the growth rates of immature males and females to substantiate their findings. However, faster male growth rates in our study (Fig. 6) coincide with observations of Schoener and Schoener (1978)

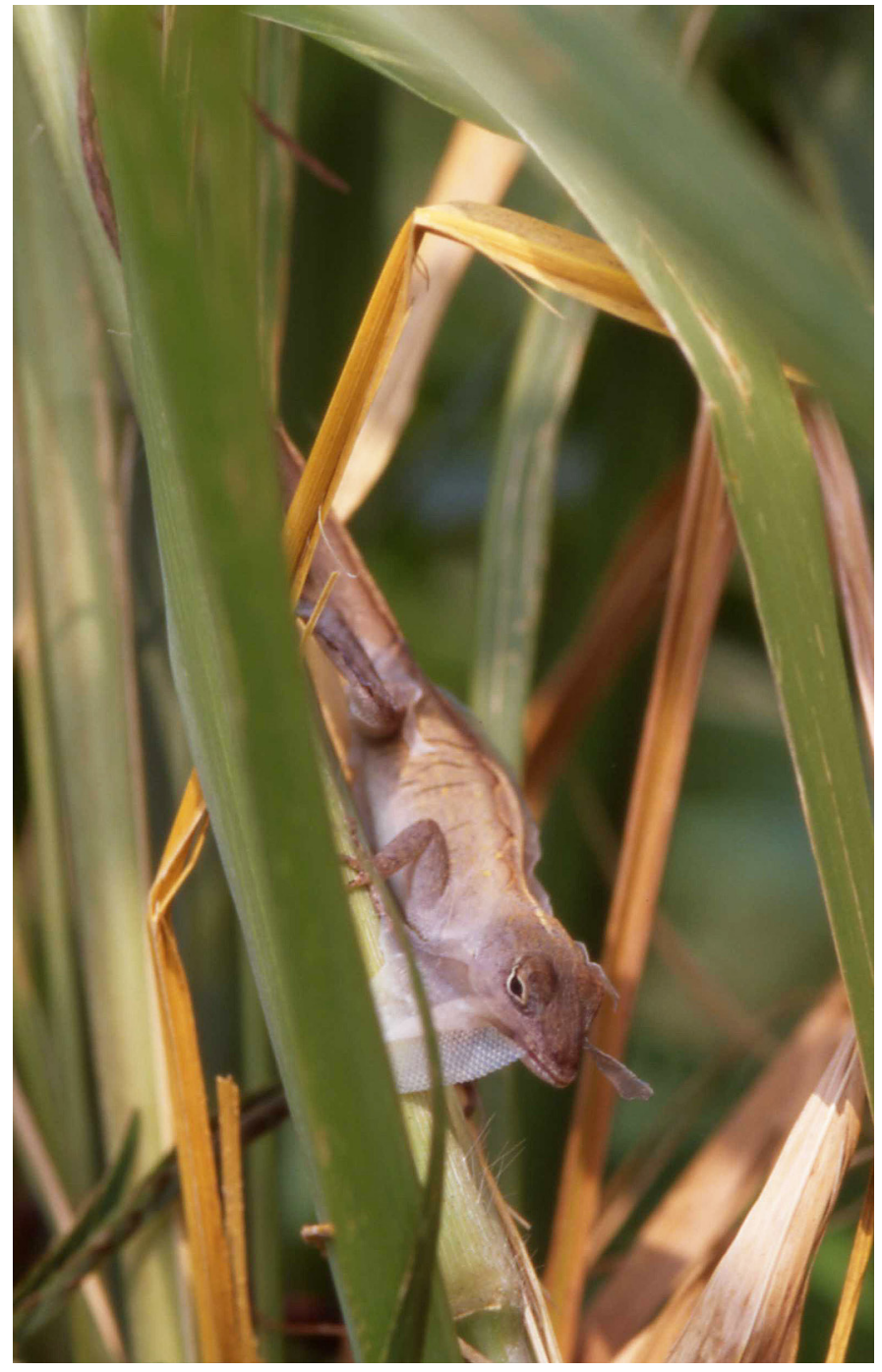

Fig. 7. An adult female Anolis sagrei from the Santzepu sampling area, consuming its sloughed skin.

and Cox et al. (2009), who noted that males grow at faster rates than females, and that males attain greater SVL due to a growth spurt. Also as per Schoener and Schoener (1978) and Cox et al. (2009), the results of our study indicate that smaller individuals have greater growth rates than larger conspecifics of the same sex. Dial and Fitzpatrick (1981) hypothesized that in short-lived iteroparous species with a low probability of future reproductive success, allocating energy to reproduction takes precedence over growth and maintenance. This appears to be the case in $A$. sagrei, and as individuals approach and reach sexually mature sizes, reproduction can be expected to become a priority, provided that conditions for reproduction are met.

Anolis sagrei males are very territorial and body size is often crucial in establishing and defending territories. Consequently, juvenile and sub-adult males should have high growth rates to attain sizes at which they can establish and defend territories. Even though relatively small males (SVL $=30-39 \mathrm{~mm}$ ) can have sperm, they are unlikely to establish 
and successfully defend territories (Norval et al. 2012a). Such males therefore probably invest more energy in growth than larger males, which would explain the higher growth rates observed in smaller males in this study.

Because larger body sizes increase the likelihood of success in territorial fights, sexually mature males can be expected to continue growing throughout their lives. However, since larger territorial males tend to spend more time defending territories and displaying as well as courting and mating with females (all energy-intensive activities), they probably devote less time to foraging. This could explain the reduced growth rates observed in our study.

If SVL MG \% of males with original and regenerated tails are pooled, and the mean SVL MG \% per month is calculated for adult $(\mathrm{SVL} \geq 39 \mathrm{~mm})$ and sub-adult males $(\mathrm{SVL}<$ $39 \mathrm{~mm}$ ), a certain pattern can be discerned (Fig. 5). The peak reproductive period for $A$. sagrei at this locality is March to August (Norval et al. 2012a), which appears to be a period of low growth for adult males (Fig. 5), suggesting that available energy is directed primarily to reproduction. Some evidence for this is the sudden increase in growth rates in September, the month during which reproductive activity in males is lowest (Norval et al. 2012a), presumably by directing more energy to growth once requirements for reproduction are met.

Females do not engage in territorial interactions with the same intensity as males, so increases in body size are not as important. However, egg production and the physical burden of carrying eggs are energy intensive (Kratochvíl and Kubička 2007, Cox and Calsbeek 2009, Cox et al. 2010). In addition, body size constrains space available for stored energy and developing eggs (Du et al. 2005). Larger females can be expected to be better able to deal with the weight burden, and the larger body cavity would also enable the production of eggs in quicker succession, provided enough energy and the right environmental conditions are present. Larger females can also be expected to be more capable of capturing larger and more energetically rich prey. Smaller females would thus benefit from investing in growth when the requirements for reproduction have been met. However, as females near an optimum size, further growth in such a short-lived species would become less necessary, and they presumably would invest less in growth and more in reproduction. This could explain the higher growth rates of smaller females in our study. Also, in many anoles (including $A$. sagrei), sexually mature females respond to available prey differently than males (Licht 1974; Stamps 1977, 1984; Schoener and Schoener 1978; Stamps and Tanaka 1981; Guyer 1988; Wright et al. 2013), and tend to direct more energy to reproduction when more prey is available, resulting in quicker egg production as opposed to higher growth rates. We are unable to evaluate egg production rates, but the growth pattern depicted in Fig. 5 is suggestive of a reduction in growth rates early in the peak breeding period (April to July) and an increase in growth rates as the breeding period comes to an end (August to September). The apparent absence of growth immediately prior and after the reproductive period probably reflects low recapture rates, but another factor could be the sizes of recaptured females. All had SVLs $>44 \mathrm{~mm}$ and most likely had reached sizes at which little growth took place. Stamps (1977) noted a similar situation in Anolis aeneus. However, observations by Wright et al. (2013) and stomach content data from Norval et al. (2010) strongly suggest that at least some females (most likely smaller individuals) grow during the non-breeding period.

Anolis sagrei is a diurnal sit-and-wait (ambush) predator that favors a variety of sunny habitat types and areas disturbed by anthropogenic activities (Schwartz and Henderson 1991). These lizards usually perch head-downward, and make frequent forays to catch prey, which are usually consumed on the ground (Schoener and Schoener 1978), after which they return to their perches (Schwartz and Henderson 1991). Studies involving Anolis carolinensis Voigt, 1832 have found that caudal autotomy impedes the jumping (Gillis et al. 2009) and sprinting (McElroy and Bergmann 2013) abilities of these lizards. Schwartz and Henderson (1991) made reference to an $A$. sagrei male (SVL not stated) that regenerated almost one inch of an autotomized tail in 26 days, and the results of our study also found that, although both males and females regenerate their tails fairly rapidly, the average rate for males is higher than that of females. Because caudal autotomy is of minor consequence to a male once it has established a territory and caudal autotomy does not result in the loss of its territory (Kaiser and Mushinsky 1994), rapid regeneration is most likely related to restoring locomotor stabilization.

The results of this study indirectly highlight the importance of conserving native lizards in areas disturbed by anthropogenic activities in Taiwan. Species such as Long-tailed Sun Skinks (Eutropis longicaudata) are not only potential competitors, but have also been observed preying on $A$. sagrei (Norval et al. 2004). In particular, species such as Swinhoe's Tree Lizard (Japalura swinhonis), which has a substantial dietary overlap with A. sagrei (Norval et al. 2012b), can be instrumental in mitigating the impact of $A$. sagrei on native ecosystems by competing with them. Studies in the Bahamas have found that in the presence of competitors or predators A. sagrei tends to be more arboreal, which results in reduced foraging opportunities and a subsequent reduction in body sizes (Schoener and Schoener 1978, Schoener et al. 2002, Losos 2009). Slower growth rates would result in smaller sizes, which could not only reduce the ability of $A$. sagrei to compete with other sympatric lizard species (Schoener et al. 2002), but could also lower egg production rates of females.

\section{Acknowledgements}

The research presented here adhered to the Guidelines for the Use of Live Amphibians and Reptiles in Field Research (SSAR, ASIH, and HL; www.aaalac.org/accreditation/Guidelines_ 
for_Use_of_Live_Amphibians_and_Reptiles.pdf) and the legal requirements of Taiwan, R.O.C. Since Anolis sagrei is an exotic invasive species in Taiwan, which the authorities wish to exterminate, and because the study was not done within a national park or other conservation area, no collection permit or other documentation was required.

\section{Literature Cited}

Butler, M.A., T.W. Schoener, and J.B. Losos. 2000. The relationship between sexual size dimorphism and habitat use in Greater Antillean Anolis lizards. Evolution 54:259-272.

Campbell, T.S. and A.C. Echternacht. 2003. Introduced species as moving targets: Changes in body sizes of introduced lizards following experimental introductions and historical invasions. Biological Invasions 5:193-212.

Chang, N.C. 2007. A new discovered alien lizard of Hualien Anolis sagrei. Natural Conservation Quarterly 57:37-41 (in Chinese).

Cox, R.M. and R. Calsbeek. 2009. Severe costs of reproduction persist in Anolis lizards despite the evolution of a single-egg clutch. Evolution 64:1321-1330.

Cox, R.M., E.U. Parker, D.M. Cheney, A.L. Liebl, L.B. Martin, and R. Calsbeek. 2010. Experimental evidence for physiological costs underlying the trade-off between reproduction and survival. Functional Ecology 24:1262-1269.

Cox, R.M., D.S. Stenquist, and R. Calsbeek. 2009. Testosterone, growth and the evolution of sexual size dimorphism. Journal of Evolutionary Biology 22:15861598.

Dial, B.E., and L.C. Fitzpatrick. 1981. The energetic costs of tail autotomy to reproduction in the lizard Coleonyx brevis (Sauria: Gekkonidae). Oecologia 51:310-317.

Du, W., X. Ji, and R. Shine. 2005. Does body volume constrain reproductive output in lizards? Biology Letters 1:98-100.

Gillis, G.B., L.A. Bonvini, and D.J. Irschick. 2009. Losing stability: Tail loss and jumping in the arboreal lizard Anolis carolinensis. Journal of Experimental Biology 212:604-609.

Goldberg, S.R., F. Kraus, and C.R. Bursey. 2002. Reproduction in an introduced population of the Brown Anole, Anolis sagrei, from O'ahu, Hawaii. Pacific Science 56:163-168.

Guyer, C. 1988. Food supplementation in a tropical mainland anole, Norops humilis. Effects on individuals. Ecology 69:362-369.

Kaiser, B.W. and H.R. Mushinsky. 1994. Tail loss and dominance in captive adult male Anolis sagrei. Journal of Herpetology 28:342-346.

Kraus, F. 2009. Alien Reptiles and Amphibians, a Scientific Compendium, and Analysis. Invading Nature: Springer Series in Invasion Biology 4. Springer, Dordrecht, The Netherlands.

Kratochvíl, L. and L. Kubička. 2007. Why reduce clutch size to one or two eggs? Reproductive allometries reveal different evolutionary causes of invariant clutch size in lizards. Functional Ecology 21:171-177.

Lee, J.C. 1987. Anolis sagrei in Florida: Phenetics of a colonizing species II. Morphometric characters. Copeia 1987:458-469.

Lee, J.C., D. Clayton, S. Eisenstein, and I. Perez. 1989. The reproductive cycle of Anolis sagrei in southern Florida. Copeia 1989:930-937.

Licht, P. 1974. Response of Anolis lizards to food supplementation in nature. Copeia 1974:215-221.
Licht, P. and G.C. Gorman. 1970. Reproductive and fat cycles in Caribbean Anolis lizards. University of California Publications in Zoology 95:1-52.

Lister, B.C. 1976. The nature of niche expansion in West Indian Anolis lizards I: Ecological consequences of reduced competition. Evolution 30:659-676.

Losos, J.B. 2009. Lizards in an Evolutionary Tree: Ecology and Adaptive Radiation of Anoles. University of California Press, Berkeley.

Losos, J.B., J.C. Marks, and T.W. Schoener. 1993. Habitat use and ecological interaction of an introduced and native species of Anolis lizard on Grand Cayman, with a review of the outcomes on anole introductions. Oecologia 95:525-532.

McElroy, E.J. and P.J. Bergmann. 2013. Tail autotomy, tail size, and locomotor performance in lizards. Physiological and Biochemical Zoology 86:669-679.

Norval, G., S.R Goldberg, and J.J. Mao. 2012a. The reproductive cycle of the Brown Anole (Anolis sagrei), an invasive lizard species in Taiwan. Russian Journal of Herpetology 19:75-81.

Norval, G., W.F. Hsiao, S.C. Huang, and C.K. Chen. 2010. The diet of an introduced lizard species, the Brown Anole (Anolis sagrei), in Chiayi County, Taiwan. Russian Journal of Herpetology 17:131-138.

Norval, G., S.C. Huang, J.J. Mao, S.R. Goldberg, and K. Slater. 2012b. Additional notes on the diet of Japalura swinhonis (Agamidae) from southwestern Taiwan, with comments about its dietary overlap with that of sympatric Anolis sagrei (Polychrotidae). Basic and Applied Herpetology 26:87-97.

Norval, G., J.J. Mao, and H.P. Chu. 2004. Mabuya longicaudata (Long-tailed Skink). Predation. Herpetological Review 35:393-394.

Norval, G., J.J. Mao, H.P. Chu, and L.C. Chen. 2002. A new record of an introduced species, the Brown Anole (Anolis sagrei) (Duméril \& Bibron, 1837), in Taiwan. Zoological Studies 41:332-336.

Okada, S., M. Izawa, and H. Ota. 2002. Growth and reproduction of Gekko hokouensis (Reptilia: Squamata) on Okinawajima Island of the Ryukyu Archipelago, Japan. Journal of Herpetology 36:473-479.

Rodriguez Schettino, L.R. 1999. The Iguanid Lizards of Cuba. University Press of Florida, Gainesville, Florida.

Schoener, T.W. and A. Schoener. 1978. Estimating and interpreting body-size growth in some Anolis lizards. Copeia 1978:390-405.

Schoener, T.W., D.A. Spiller, and J.B. Losos. 2002. Predation on a common Anolis lizard: Can the food-web effects of a devastating predator be reversed? Ecological Monographs 72:383-407.

Schwartz, A. and R.W. Henderson. 1991. Amphibians and Reptiles of the West Indies: Descriptions, Distributions and Natural History. University Press of Florida, Florida.

Sexton O.J. and K.M. Brown. 1977. The reproductive cycle of an iguanid lizard Anolis sagrei, from Belize. Journal of Natural History 11:241-250.

Stamps, J.A. 1977. Rainfall, moisture and dry season growth rates in Anolis aeneus. Copeia 1977:415-419.

Stamps, J.A. 1984. Growth costs of territorial overlap: Experiments with juvenile lizards (Anolis aeneus). Behavioral Ecology and Sociobiology 15:115-119.

Stamps, J.A. and S. Tanaka. 1981. The influence of food and water on growth rates in a tropical lizard (Anolis aeneus). Ecology 62:33-40.

Williams, E.E. 1969. The ecology of colonization as seen in the zoogeography of anoline lizards on small islands. The Quarterly Review of Biology 44:345-389.

Wright, A.N., J. Piovia-Scott, D.A. Spiller, G. Takimoto, L.H. Yang, and T.W. Schoener. 2013. Pulses of marine subsidies amplify reproductive potential of lizards by increasing individual growth rate. Oikos 122:1496-1504.

Zug G.R., L.J. Vitt, and J.P. Caldwell. 2001. Herpetology. An Introductory Biology of Amphibians and Reptiles. 2nd ed. Academic Press, San Diego. 